\title{
Coping with Involuntary Job Loss and Building a New Career: Workers' Problems and Career Professionals' Challenges
}

\author{
Jeanne Prial Gordus
}

\begin{abstract}
INTRODUCTION
The major regional and sectoral shifts taking place within the American economy continue to result in large-scale worker displacement. The workers displaced are, by and large, individuals who have relatively long tenure on their jobs. The results of several decades of research on the labor market prospects of older workers faced with involuntary unemployment and forced career change have identified some major problems confronting the unemployed individual. These problems are now challenges to the career development professionals who will
\end{abstract}

Jeanne Prial Gordus is Director, Employment Transition Program and Associate Research Scientist, Industrial Development Division, Institute of Science and Technology, University of Michigan, Ann Arbor, MI.

The service program and the research projects reported here were supported by the U.S. Department of Education's Fund for the Improvement of Postsecondary Education. Lynn De Meester of the Fund was particularly helpful to us. Continuation of the program, especially as a randomized field experiment, was supported by the Center for Work and Mental Health, National Institute of Mental Health through its funding of the Michigan Prevention Research Center (NIMH 5P50MH038330). 
design programs to assist this new type of unemployed individua ?.

However, in contrast to the displacement due to plant closings and technological change in earlier periods, worker displacement in the past decade has occurred more rapidly, and more pervasively. occupations that did not exist forty years ago, such as keypunch operators, became growth occupations twenty years ago and have now virtually disappeared. Entire industries have been displaced from a high-wage region or country and have moved. The American textile industry underwent a shift to the southern states and now is undergoing internationalization, as is the American shoe industry. Vuinerability to such massive changes is not limited to manufacturing, since jobs within the service sector, the retail trade sector, and the financial sector, which are not so subject to relocation, undergo employment contraction due to automation. So, the problem of involuntary mid-life career change, always difficult, will become more prevalent more rapidly than ever before. This challenge to career development professionals requires that research findings and insights from program findings in this area be disseminated and utilized rapidly.

Career development professionals, for the most part, were trained when involuntary unemployment and career shifts for mid-life adults were not common. Moreover, the problems confronting both those losing jobs and those who might help the displaced elude traditional disciplinary lines. Labor economics, sociology, psychology, and public health have importance to these issues, yet no one area provides the answer. There is also a discontinuity between research in this area and the immediate and pressing needs of practitioners. In the sections below, earlier research findings are presented as potentially important program issues--program-related variables--and descriptions of how these issues were transformed into modules for a career-shift/job-search program are given. Preliminary data from the evaluation of this career-shift/job-search program are shown and the resemblances between this experimental, research-based program and other field-based programs are emphasized.

Finally, the fact is also stressed that involuntary unemployment dramatically heightens risk for negative physical and mental health outcomes and that unemployment-related behavioral changes tend to reduce employability. Even more important to the career development professional is the fact that the unemployed are in need of support in order to prevent adverse mental and physical health consequences. Many do not seek mental health services. Instead, they seek career development services. 
This poses an additional challenge to the career development specialist.

\section{SPECIFICATION OF THE PROBLEM}

During 1979 through late 1983, American businesses suffered from cyclical downturns, international inroads in areas of productions traditionally dominated by American firms, technological changes, and a drive to reduce employment so as to increase productivity. This combination of factors provided challenges for American workers and career development professionals; both groups learned a great deal from their experiences.

First, we learned that we lack useful information about where and when jobs will be available. It also became clear that we had little idea of the skills required for those new, emerging occupations that were discussed so much, and observed so little. Given the complexity and pervasiveness of the unemployment problem, there were serious difficulties for workers and professionals; those difficulties were associated with lack of information about present and future labor market demand.

The recession also increased awareness of a qualitative issue. The jobs that were disappearing tended to include few skills, obsolete skills, or firm-specific skills. Therefore, most individuals whose jobs disappeared often had a skill package, derived from that job, which did not conform to the skills required for available jobs. In most cases, even those who could compete found that the wage rates in new occupations were lower than in their previous occupation. This difference caused great difficulties both for job-seekers and for those who worked to assist them. In general, real or perceived deficiencies in this new labor supply, displaced workers, was exacerbated by the high wage expectations of these workers, further complicating the problems of matching these workers to available opportunities in the labor market.

Essentially, those unemployed in mid-career and those who sought to help them were faced with insufficient information about the labor market, a job-derived skill package that appeared relatively unattractive, a high probability of downward economic mobility that was unappealing to job-seekers and--one item yet unmentioned--a tendency for help-seekers and help-givers to misunderstand one another.

In the future we can expect little improvement in the quality and timeliness of labor market information unless the 
institution with which we work has a cadre of skilled job developers and access to the best of the new computerized job-search assistance systems. In many cases, we can expect that the job-derived skill package that the unemployed will present will continue to appear inadequate. We can probably also expect, in many cases, that the outcome of the career shift process will be a lower wage rate. These are the difficulties faced by job-losers and those who work in career development.

\section{REFRAMING AND SOLVING THE PROBLEM}

Another result of the recession was the development of specially designed or redesigned programs for displaced workers. Many types of skills training emerged, primarily in the nation's 1,219 community and junior colleges. Basic skills programs, designed to bring previously employed adults with literacy and computational deficiencies, developed in many organizational contexts. Finally, there was new development as well as redesign of programs originally developed to help disadvantaged groups to enter the labor market to fit them to the needs of the previously employed. A number of these programs have been very successfut (Acosta, Catalano, Gordus, Rayman, et al., 1985). One of these programs, situated at the University of Michigan, resembles many of the others but differs in that it was research-based and could be quantitatively evaluated. What we have learned quantitatively from this program has also been learned in practical terms from other similar programs.

The Employment Transition Program has had experience with many groups of unemployed individuals, from those who are employment and training specialists themselves, through Ph.D. holders in nuclear engineering, telephone operators, salespeople, teachers, and manufacturing operatives. More difficulties are faced by manufacturing operatives, especially from the auto, steel, and appliance industries, than are encountered by other groups. For that reason, this report will focus on autoworkers, since programs successful with them can easily be adapted to help other groups to successfully change careers.

The Employment Transition Program identified a series of program-related variables as being significant problems for job-seekers and career specialists, including labor market information, inadequate job-derived skill packages, and wage expectations that exceed wages currently offered to new hires. Two others should be added: the probability of little experience in recent job search and the high probability of low self-esteem. 


\section{The Labor Market Information Problem}

While aggressive job developers are a blessing to all involved in mid-life career changes, job developers are not always available. However, job-seekers themselves can learn to scout the local labor market as successfully as job developers can do it for them. The first step in helping individuals to begin this process is to have an entire group (we usually work with 15-20 in a group) think of occupations and list them. We then issue the challenge to everyone in the group to provide, for at least one occupation, the name of someone who is either in that occupation, who works for someone with that job title, or who knows somebody who knows somebody who is in that occupation. The object of that exercise is to show that anyone who has 15-20 acquaintances and the title of a job, can--that very evening-call someone and get preliminary information about an occupation and the names of other people to contact. Not only can a program participant get that assistance, but he or she can give that indirect assistance to somebody else. This helps the person giving the information because giving assistance to someone else builds self-es teem.

\section{Inadequate Job-derived Skill Packages}

In our recent survey of autoworkers, we found that the correlates of a highly successful, unassisted job search at relatively high wage rates were the possession of a bachelor's degree or a journeyman's card. However, some autoworkers without these credentials found work without assistance, generally because they had skills derived from other sources than their auto jobs, such as community volunteer work, a rich source of skills.

Our program participants find buried skills as they work out their detailed life histories. We assign participants into triads and have them share their histories. We also train them to interview and probe to extract every possible transferable skill from each other. This process takes much longer than a similar computer-based exercise but this peer interviewing and assessment seems to validate the possessions and importance of previously unused skills. The use of a computer-based skills assessment program after this exercise reinforces this important insight. Autoworkers, supposedly unskilled, and often with some basic skill deficiencies, do in fact have many marketable skills derived from their life experience. Further, data from several sources show that displaced workers with basic skills deficiencies, when provided intensive basic skills training, make very rapid strides in adult basic education. 
Wage Expectations

Those earning $\$ 10.00-15.00$ or more per hour, who, after displacement, can only find jobs at $\$ 5.00$ or less per hour, are reluctant to believe this and to accept lower paying jobs. Few other issues are as destructive to the relationship between the the job-seeker and the career change specialist than this.

A job-seeker can be excused for resenting the fact that his or her marginal product has declined in value by $50 \%$ or more. But this professional providing assistance, who normally has at least one or more years of education after the B.A. level but lower earnings than autoworkers, often experiences resentment destructive to the helping process. A cycle of misunderstanding often develops at this point. A method that we have found effective in reducing this problem is a discussion of comparative wage rates and lifetime earnings. Those entering the auto industry do earn very well, but they reach their ceiling very rapidly and are thereafter confined to the increases obtained through the collective bargaining agreement. Professionals and others earn lower wage rates at the outset--often after several years' investment in education--but multiple career tracks are open to them and their earnings have an upward trajectory over their lives, not a flat pattern altered only by negotiated upward ratcheting.

This discussion assists the mid-life job-seeker to see that promotion and merit increases can likely compensate at a later point for a low entry-level wage. Continued discussion about what entry-level wage rates are like at other establishments also serves to reduce the wage expectations of displaced autoworkers. We measured the wage expectations of a group of 255 autoworkers with whom we worked the day they began our intensive five-day program, and again on their fifth and final day. Their average wage expectation was $\$ 6.49$ on the first day and $\$ 5.97$ on the fifth day, a decline of $8 \%$.

Lack of Experience at Job Search

Experience at job search is a valuable skill; in fact, some economists consider it human capital in the same way that they assess formal education. Many community colleges are now awarding postsecondary credit for job search assistance programs. Because successful job search depends upon an understanding of several types of behavior (employer search behavior, employee search behavior, productivity signals, and the establishment and utilization of certain types of networks), it is a highly cognitive activity. Understanding these types of behavior is helpful to adults because they can then recognize the principles 
underlying the advice they hear from career development professionals.

Employers' search behavior is one that displaced autoworkers had difficulty understanding. They felt that "it isn't what you know, it's who you know" was not only true, but also unfair. However, a round robin among autoworkers asking how they got their job in the industry usually produced between $60-75 \%$ who had a family member or close friend in the plant who let them know about new hiring. Why this is rational behavior for employers, then, becomes clear: Employers know that friends and relatives of current workers are likely to resemble those current workers with whom the employer is satisfied.

At this point, the reason for establishing, using, or expanding personal networks becomes clear. Associating with people currently employed in other occupations can provide valuable training advice and employment assistance. Often, a brief discussion of how personal networks tend to change over the life cycle promotes lively discussion and also reveals why the mid-life career change is often woefully lacking in 'contacts' useful to job search. Working adults tend to limit their acquaintances to family, co-workers, neighbors, and church and school associations, simply because they are busy. These networks are often less than useful because often family members, friends, and neighbors are also co-workers and in the same jobless situation. Broadening the circle of association is particularly crucial at this time--and it is also particularly difficult.

\section{Low Self-Esteem}

Low self-esteem is associated with unemployment, and prolonged unemployment accelerates the problem (Bowman, 1982). A feeling that one has lost personal control over life events contributes to low self-esteem.

Often, low self-esteem occurs in tandem with self-blame. Unemployed individuals blame themselves for being unemployed, remaining unemployed, and, in the case of autoworkers, for having succumbed to the lure of high wages instead of continuing their education.

Cognitive restructuring can help the structurally unemployed deal with feelings of low self-esteem and self-blame, but only if enough time is allowed and permission given to share their feelings. First, these individuals must understand that it is normal for people who are unemployed to experience mood swings, situational depression, isolation, sleep disturbances, and nervousness. 
Low self-esteem can be dealt with by showing them how they can remedy their current situation and that their career change, while not easy and risk free, can be done successfully. Selfblame can be dealt with by pointing out that their situation-structural unemployment--is not their fault. If individuals in the group blame themselves for not continuing their education but, instead, accepted well-paying jobs, a discussion in which the lifetime earnings of autoworkers, for example, are compared to those of educators and training professionals is helpful.

This discussion will demonstrate that those who chose the initial high wages of, say, the auto industry may have made a more rational economic choice than many professionals.

\section{RESULTS}

The Employment Transition Program has been evaluated, however, for the several hundred autoworkers, the design of the evaluation was quasi-experimental. However, in association with the Michigan Prevention Research Center at the University of Michigan, a major intervention research program, the Employment Transition Program has been presented to individuals randomly assigned to treatment and control status. Preliminary findings from the first pre-test for the program show the following results after the first follow-up.

Reemployment and Unemployment After 10 Weeks

\begin{tabular}{lcc}
\hline GROUP & UNEMPLOYED & REEMPLOYED \\
\hline CONTROL & $88 \%$ & $12 \%$ \\
\hline TREATMENT & $55 \%$ & $45 \%$ \\
\hline
\end{tabular}

This was a small group, having about 60 individuals in the treatment group and 60 in the control group. Currently a much larger group is being studied; individuals were randomly assigned to one of two groups. One group is receiving a full range of services; the other group is using a low-level, self-paced "paper package" for job search. 


\section{DISCUSSION}

In reviewing the content of many successful programs for displaced workers, it is clear that the same problems identified here are addressed by other programs. Often, the style of addressing the problems differ. Generally, the development of a highly structured and cognitive program occurs within a research context. Virtually all program modules have developed from a research base in labor economics, sociology, or psychology. The modules were designed consciously as interventions that could be measured and the findings added to the research base. However, the same general approach, though seldom as self-conscious, is present in many similar programs. The importance of a group and the facilitation of supportive behavior among group members are major elements for those in mid-life for whom job loss is particularly traumatic.

Adult learners respond very poorly to job search advice they feel is purely academic; yet they respond very enthusiastically when given the underlying theory and data supporting the advice. In fact, a major element in the positive response our program and others have received is that these programs provide a framework for understanding a very painful personal experience. The process of coming to understand that which is threatening and painful reduces the threat and pain and makes the development and implementation of a personal action plan possible.

\section{MAINTAINING MENTAL HEALTH AND BUILDING SUCCESSFUL NEW CAREERS}

The program we have described above, and others like it, are within the province of the career development specialist. Whether associated with schools, colleges, universities, agencies, companies, communities, or unions, the programming we have described for mid-life job-losers is the first contact many of them have with the helping professions.

However, unemployment increases the risk for alcohol, drug abuse, and negative mental health outcomes. Job-losers do not, however, seek mental health services, although the mental health community is aware of the risks associated with unemployment and often wishes to serve the needs of this group. Consequently, although career development professionals are not mental health professionals, they have a major role in providing some support to job-losers, which will prevent the onset of serious personal difficulty. The vast majority of those displaying some symptoms of depression subsequent to job loss will immediately display cessation of symptoms when a new job is found. However, research and experience indicates that depression caused by low self- 
esteem and self-blame can also be relieved by simple initiatives. The provision of ample time and a supportive atmosphere for sharing experiences, as described earlier; invitations to spouses and older children to come to a program in the evening to meet others and share in a family solution to unemployment; facilitating a follow-up support group for individuals or families; and even the conscious decision on the part of the career development professional to "brown bag" it with the participants at lunch time are excellent mental health preventive strategies and are supportive to productive job search. Career development professionals presenting good and effective mid-life career change programs often do many of these things as part of a program designed to provide coping skills as well as job search skills, little realizing that they are providing preventive mental health services.

\section{RESOURCES AND PROGRAM BUILDING FOR THE FUTURE}

As need continues and increases for career development assistance for mid-life job-losers, it becomes even more important to think in terms of early intervention. What we have discussed above is, in terms of timing, the least desirable type of intervention for unemployed individuals. It is remedial and after the fact. Intervention programs that are implemented between the time the layoff announcement is made and layoff actually occurs are clearly preferable to those interventions that occur later. By allowing individuals time to engage in job search programs, retraining, and other forms of assistance prior to layoff, some individuals may completely avoid unemployment and others endure a briefer period of unemployment.

The most ideal situations, however, are those in which a type of "inoculation" against the potential of job loss can be implemented. Working adults, especially in the occupations most vulnerable to employment contraction, have tended to transfer control over the development of their careers to their employer. Continuing education programs that provide assistance in rebuilding some basic skills and which also provide needed skills for emerging jobs, both with the current employer and in other establishments, are clearly a critical need.

If one lesson stands out as the most important one learned from our recent experience with job loss and career change programming, it is that career planning is a continuing process in which all working adults should engage on a regular basis. Prevention of job loss and its traumatic aftermaths must start where those losses are most severe, with the people affected. Career development professionals, whose services are so important to the crises associated with mid-life career change, must also 
highlight the degree to which the lack of systematic career development services has added to the problems of worker displacement.

\section{REFERENCES}

Acosta, F. X., Catalano, R. A., Gordus, J. P., Rayman, P., et al. (1985). Unemployment and mental health: A report on research resources for technical assistance (Prepared for the National Institute of Mental Health, Washington, D.C.).

Bowman, P. (1982, August). Social psychology of discouragement among jobless black Americans: Research agenda, preliminary analysis, and implications. Paper presented at the meeting of the American Psychological Association, San Francisco, CA. 